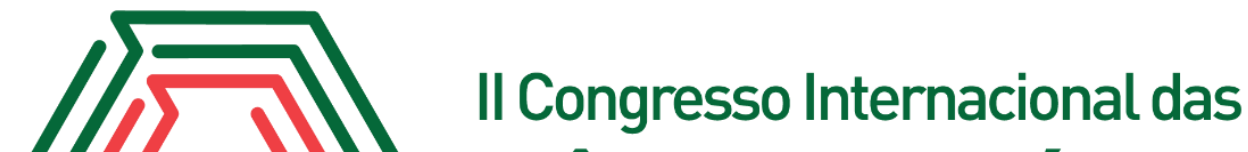 Ciências Agrárias COINTER - PDVAgro 2017
}

\section{COMPOSIÇÃO CENTESIMAL DA CARNE DE CABRITO CONSERVADA COM ERVA- SAL (Atriplex nummulária)}

\author{
Apresentação: Pôster
}

\begin{abstract}
Maria Raquel Lopes Silva ${ }^{1}$; Uri Vanille Raiol da Silva ${ }^{1}$; Ana Paula Pinheiro de Assis ${ }^{2}$; Lucas de Oliveira Soares Rebouças ${ }^{3}$; Patrícia de Oliveira Lima ${ }^{4}$
\end{abstract}

\section{Introdução}

A carne caprina vem se sobressaindo ao longo dos últimos anos como uma boa opção de consumo, seja pelo seu valor nutricional ou pela sua qualidade sensorial. $\mathrm{O}$ valor comercial da carne tem sido baseado no seu grau de aceitabilidade pelos consumidores, e está diretamente correlacionado aos parâmetros de palatabilidade do produto (CABRAL, 2011).

Nos últimos anos há um crescente interesse pela carne caprina, principalmente de animais jovens, em função de suas propriedades nutricionais, pois apresentam baixos teores de colesterol, gordura saturada e calorias, além de elevados níveis de proteína (MADRUGA, 1999).

Assim, objetivou-se avaliar a influência da erva- sal (Atriplex nummulária) sobre a composição centesimal da carne de cabrito, como aditivo ou conservante.

\section{Fundamentação Teórica}

A carne caprina é de excelente qualidade nutricional, com baixos teores de gordura e elevado percentuais proteicos, associado às excelentes características sensoriais. Com relação à qualidade e quantidade das proteínas da carne caprina, pode-se dizer que essa carne é excelente fonte nutricional e apresenta diferenças em sua composição química em seus diferentes tipos de cortes. Existe relação entre a suculência da carne e a idade do animal, ou seja, quanto menor a idade do animal, maior a suculência de sua carne, devido à maior capacidade de retenção de água, e

\footnotetext{
${ }^{1}$ Mestranda do programa de pós-graduação em produção animal - UFERSA, Mossoró- RN, Brasil, Raquellopes16@hotmail.com,

${ }^{2}$ Mestre em Ciência Animal - UFERSA, Mossoró - RN, Brasil, pinheiropaula87@hotmail.com

${ }^{3}$ Mestre em Produção Animal - UFERSA, Mossoró - RN, Brasil, lucaslosr@gmail.com

${ }^{4}$ Docente na Universidade Federal Rural do Semi-Árido - UFERSA, Mossoró-RN, Brasil, pattlima@ufersa.edu.br
} 
consequentemente menor perda de água durante o cozimento (MADRUGA et al., 2005).

A carne de caprinos jovens é caracterizada por baixo conteúdo de gordura intramuscular e subcutânea (SHERIDAN et al., 2003), o que, atualmente, está de acordo com os interesses dos consumidores, que valorizam o baixo teor de gordura dos alimentos. A umidade, teor de água, de um alimento constitui um dos mais importantes e mais avaliados índices em alimentos, sendo de grande importância econômica por refletir o teor de sólidos de um produto e a sua perecibilidade. A gordura da carne, além do aspecto energético, é importante pelos ácidos graxos essenciais, colesterol e vitaminas lipossolúveis, sendo também indispensável para os aspectos organolépticos de sabor (GOMES, 2011). A maioria das substâncias nitrogenadas da carne é substituída pelas proteínas que são os componentes mais abundantes, superados unicamente pela água e, em alguns casos, pela gordura. As proteínas da carne são similares em todos os animais, sendo classificadas segundo sua solubilidade em proteínas sarcoplasmáticas, miofibrilares e insolúveis (ORDOÑEZ, 2005). A matéria mineral tem a função de manter a pressão osmótica das células. Está associada à água e à proteína; portanto, é encontrada em maior quantidade em músculos magros, em percentual de $1 \%$ (BONAGURIO, 2001).

A erva-sal (Atriplex nummulária) é um arbusto forrageiro originário da Austrália esta espécie de planta pertence ao grupo das halófitas, que tem habilidade para suportar altos níveis de salinidade, e, de acumular significativas quantidades de sais em seus tecidos (ARAÚJO e PORTO, 2000). Utilizada no semiárido, principalmente como fonte de alimentação para animais ruminantes, a erva-sal (Atriplex nummularia) apresenta um potencial para ser usada na conservação da carne bovina, devido à significante quantidade de sais presente nos seus tecidos (CARVALHO et. al., 2015).

\section{Metodologia}

As amostras de carne de cabrito foram obtidas de um produtor na cidade de Lajes - RN. Estas foram cortadas em amostras com aproximadamente $150 \mathrm{~g}$ e com 3 centímetros de espessura. Logo após as carnes foram separadas em quatro grupos: C1E: carne com 1\% de adição de erva sal; C2E: carne com 2,5\% de adição de erva sal; C5E: carne com 5\% de erva sal e; CSE: Carne sem adição da erva sal.

Após os tratamentos as carnes foram acondicionadas em bandejas de poliestireno cobertas com plástico filme e armazenadas sob refrigeração. As leituras foram realizadas em espectrofotômetro de infravermelho próximo (NIRS) da Perstorp Analytical Company, modelo 
6500 (Silver Spring, MD, EUA) equipado com detector de reflectância, na faixa de 1.100 a 2.500 $\mathrm{nm}$, em intervalos de $2 \mathrm{~nm}$, utilizando célula coarse com janela de quartzo. Antes das leituras espectrais, as amostras foram picadas em cubos, homogeneizadas e compactadas ao serem colocadas na célula para leitura espectral, visando eliminar problemas de leitura surgidos pelo efeito de superfície. Para garantir que variações extremas de temperatura não interferissem na coleta dos espectros, o equipamento foi mantido em uma sala climatizada com temperatura de aproximadamente $25^{\circ} \mathrm{C}$. Para cada amostra, foram armazenados espectros em três repetições (em torno de 20 segundos para cada leitura), sendo coletados da seguinte maneira: (1) procedeu-se a primeira leitura e o espectro foi armazenado; (2) posteriormente, a amostra foi retirada da célula, misturada com o restante da mesma amostra e então colocada novamente na célula para a coleta de outro espectro por NIRS e; (3) repetiu-se o mesmo procedimento para a coleta do terceiro espectro. Cada espectro obtido foi armazenado na biblioteca de espectros para posteriormente serem submetidos aos tratamentos estatísticos.

Os dados foram submetidos à análise de variância e teste de comparação de médias. Os efeitos dos diferentes tratamentos sobre cada variável foram comparados por meio do teste de Tukey, ao nível de 5\% de probabilidade, com auxílio do programa estatístico SAS (2010).

\section{Resultados e Discussões}

No que se refere à composição centesimal houve diferença estatística $(\mathrm{P}<0,05)$ entre os tratamentos utilizados, observando-se que quanto maior a concentração de erva-sal menor o teor de umidade, como mostra a Tabela 5. Esses valores são inferiores aos valores encontrados por Assis et al., (2015) que obtiveram valores médios em cabritos SRD entre 77,43\% a 74,87\%, e afirma que animais com pouca idade o teor de umidade é maior, por apresentarem pouca quantidade de gordura em sua carcaça,

Tabela 1: Valores médios da composição centesimal da carne de cabrito durante armazenamento de carne refrigerada, adicionada de erva - sal (Atriplex nummulária).

\begin{tabular}{|c|c|c|c|c|c|}
\hline \multirow[t]{2}{*}{ Variáveis } & \multicolumn{4}{|c|}{ Concentrações de Erva- Sal } & \multirow[t]{2}{*}{$\mathrm{CV}(\%)$} \\
\hline & $0 \%$ & $1 \%$ & $2,5 \%$ & $5 \%$ & \\
\hline Umidade & $37,63 \mathrm{a}$ & $34,74 \mathrm{a}$ & $34,17 \mathrm{ab}$ & $30,25 \mathrm{~b}$ & 4,57 \\
\hline Proteína & $25,24 \mathrm{~b}$ & $31,45 \mathrm{a}$ & $31,62 \mathrm{a}$ & $32,53 \mathrm{a}$ & 3,55 \\
\hline Extrato etéreo & $0,91 \mathrm{c}$ & $1,92 \mathrm{bc}$ & $2,62 \mathrm{ab}$ & $3,16 \mathrm{a}$ & 17,86 \\
\hline Cinza & $1,62 b$ & $3,65 \mathrm{a}$ & $5,10 \mathrm{a}$ & $0,85 \mathrm{~b}$ & 20,11 \\
\hline
\end{tabular}


A, b, c Letras diferentes distintas na linha indicam diferença entre os tratamentos pelo teste Tukey 5\%.

Quanto ao teor de proteína a carne que recebeu a maior concentração de erva-sal teve o maior valor médio protéico $(\mathrm{P}<0,05)$. A melhoria do teor nutricional da carne, especificamente o teor protéico, enriquece o produto, e pode ser atribuído à qualidade protéica da erva sal, onde foi usado basicamente os ramos e folhas das plantas, que segundo Porto et al. (2001), podem corresponder a $81,7 \%$ do percentual produzido por parte da planta.

O maior teor de gordura foi no tratamento C5E e o menor no tratamento CSE, mostrando que o extrato etéreo aumentava de acordo com o acréscimo dos tratamentos. Os valores médios exibidos para o extrato etéreo desse estudo se encontram de acordo com os valores apresentados na literatura, como mostra Rodrigues et al. (2010), que obteve média de 2,19\% de extrato etéreo.

Para os valores médios de cinza, não houve diferença estatística $(\mathrm{P}<0,05)$, mas, de acordo que se aumenta a concentração da erva-sal os valores de cinza também aumentam, que pode ser atribuído a erva-sal, já que está possui mecanismos especializados de acumulação de sais no seu interior e de eliminação destes através das folhas (BARROSO et al., 2006).

O nível de adição de 5\% erva-sal (Atriplex numulária) aumentou o valor protéico, o extrato etéreo e a cinza. Além de diminuir os valores médios da umidade.

\section{Conclusões}

A inclusão da erva-sal (Atriplex nummulária) em níveis crescentes como conservante natural influenciou na composição centesimal da carne.

\section{Referências}

ARAUJO, G. G .L.; PORTO, E. R. Produção e composição química de erva sal, irrigada com rejeito da dessalinizaçãoo de água salobra. In: congresso nordestino de produção animal, 2.; simpósio nordestino de alimentação de ruminantes, 8., 2000, Teresina. Anais...Teresina: Sociedade Nordestina de Produção Animal, 2000. v.2, p. 115-117.

ASSIS, Ana Paula Pinheiro de. parâmetros físicos e químicos da carne de cabritos alimentados com diferentes dietas líquidas até os 60 dias1. Acta Veterinaria Brasilica, Mossoró, v. 4, n. 9, p.327-334, 2015.

BONAGURIO, S. Qualidade da carne de cordeiros Santa Inês puros e mestiços com Texel abatidos com diferentes pesos. 2001. 149f.. Dissertação (Mestrado em Zootecnia) - Universidade Federal de Lavras, Lavras, 2001.

BARROSO, D. D. et al. Produtividade e valor nutri-tivo das frações forrageiras da erva-sal (Atriplex nummularia) irrigada com quatro diferentes volumes de efluentes da criação de tilápia em água salobra. Agropecuária Técnica, Areia, v. 27, n. 1, p. 43-48, 2006. 
CABRAL, Humberto Barbosa. Qualidade da carne de caprinos SRD e seus cruzamentos com Boer e Anglo Nubiano terminados em confinamento. 2011. 75 f. Dissertação (Mestrado) - Curso de Programa de Pós-graduação em Ciência e Tecnologia de Alimentos, Universidade Federal da Paraĺba, João Pessoa, 2011.

CARVAlHO, M. F., EL-DEIR, S. G., CORRÊA, M. M., CARVALHO, G. C.Estudo de caso de três espécies de plantas bioindicadoras de solos salinos. Revista Verde de Agroecologia e Desenvolvimento Sustentável, v. 10, n. 3, p. 01-08, 2015.

GOMES, J. C. Análises físico-químicas de alimentos. 1 ed, Editora UFV. Viçosa, 2011.

MADRUGA, M.S. 1999. Artigo técnico: Carne caprina: Verdades e mitos à luz da ciência. Rev Nac Carne, 264: 34-40.

MADRUGA, M. S.; NARAIN, N.; DUARTE, T. F.; SOUZA, W.H.; GALVÃO, M. S.; CUNHA, M. G. G.; RAMOS, J. J. F; A Características químicas e sensoriais de cortes comerciais de caprinos SRD e mestiços de Bôer. Ciência e Tecnologia de Alimentos., Campinas, 25(4): 713-719, out.-dez. 2005.

ORDOÑEZ, J.A. Tecnologia de Alimentos. Vol 2, Artmed. Porto Alegre, 2005

PORTO, E. R.; AMORIN, C. C. . SILVA JÚNIOR, L. G. Uso do rejeito da dessalinização de AGU salo- bra para irrigação da erva-sal ( Atriplex nummularia ). Revista Brasileira de Engenharia Agrícola e Am biental, Campina Grande, v. 5, n. 1, p. 11-114, 2001

RODRIGUES, Luciana et al. Somatotropina bovina (rbST) recombinante sobre as características físico-químicas da carne de cabritos. Revista Brasileira de Ciências Agrárias, Recife, v. 5, n. 4, p.606-612, 2010. Mensal.

SANTOS, C.L.; Perez, J.R.O.; Muniz, J.A.; et al. Desenvolvimento relativo dos tecidos ósseo, muscular e adiposo dos cortes da carcaça de cordeiros Santa Inês. Revista Brasileira de Zootecnia, v. 30, n. 2, p. 487-492, 2001.

SHERIDAN, R.; HOFFMAN, L.C.; FERREIRA, A.V. Meat quality of Boer goat kids and Mutton Merino lambs. 1. Commercial yields and chemical composition. J. Anim. Sci., v.76, p.63- 71, 2003. 